\title{
Intermodal Transport of Ethanol in Brazil: A Simulation
}

\section{Using Partial Equilibrium}

\author{
Jamile de Campos Coleti $^{1}$, Andrea Leda Ramos de Oliveira ${ }^{2}$ and Karina Braga Marsola ${ }^{2}$ \\ 1. Institute of Economics, University of Campinas, Campinas 13083-857, Brazil \\ 2. School of Agricultural Engineering, University of Campinas, Campinas 13083-875, Brazil
}

\begin{abstract}
The search for renewable energy has put ethanol on another level, making Brazil the second largest producer in the world. The aim of this study was to analyze ethanol transportation alternatives in the face of the current logistics in Brazil. It was proposed a partial equilibrium model analyzing three scenarios: the first concerned a base scenario (scenario 1), the second estimated a $15 \%$ decrease in railroad freight (scenario 2), and the third included new national pipeline projects (scenario 3). Scenario 3 showed the highest trading volumes with a $0.20 \%$ increase compared with the base scenario, indicating transport systems that prioritize multimodality. It was also highlighted that the multimodality assumptions of scenarios 2 and 3 resulted in competitiveness gains in the international market, because all the routes destined for foreign markets are multimodal.
\end{abstract}

Key words: Economics, logistics, agriculture, ethanol, simulation.

\section{Introduction}

The expansion of Brazilian agribusiness has been characterized by increasingly integrated production chains and the intensive use of capital in the various segments that comprise them. Agriculture in Brazil is still distinguished by its high share of GDP, ongoing trade surplus and contribution to controlling inflation [1]. Indeed, while Brazilian agro-industrial systems are highly developed and further growth is expected in this sector, new challenges, such as the domestic logistics system are rising to prominence.

This study focuses on the use of ethanol. Brazil is the world's second largest ethanol producer [2]. For 2015/2016, the harvest in Brazil has been estimated to total 29.2 million cubic meters, only lagging behind the United States (50.4 million cubic meters) [3]. The increase in oil price, strong demand for clean and renewable sources of energy and intense commercialization of flex-fuel cars has created a favorable scenario for biofuel production. Ethanol also

Corresponding author: Jamile de Campos Coleti, Ph.D. student, research field: agricultural economics. has environmental advantages, as its combustion generates less carbon dioxide than gasoline.

Transport managers are usually responsible for making decisions on whether to use own transport or an external company, while they are also responsible for the choice of the optimal route of transporting cargo [4]. Currently, Brazil operates with five modes of transport, namely road, railroad, waterway, pipeline and air, with most agricultural commodities transported by road. Plants are usually located in agricultural regions with difficult access to major transport routes and, owing to their production value, investment in non-road transport modes is unfeasible [5].

Railroads have high fixed costs and are slow despite offering a higher cargo transport capacity, which may generate economy of scale [6]; hence, rail is recommended for solid bulks, large quantities and longer travel distances. Nevertheless, the use of railroads for ethanol transport has increased in the past three years for a number of factors, such as lowering product costs, increasing competitiveness in foreign markets, reductions in traffic congestion on port 
routes and environmental improvements from the reduction of carbon emissions [7]. Further, some investments in alcohol pipelines are planned to overcome the bottlenecks in the fuel transport market and improve competitiveness [5]. One example is the Logum project, an intermodal pipeline/railroad complex across five states: São Paulo, Rio de Janeiro, Goiás, Minas Gerais and Mato Grosso do Sul.

According to the data, there are approximately 329 fuel distribution bases in Brazil. Ethanol transport starts at one of the production units. Then, ethanol is transferred to collection centers for storage, or may be directly transferred to the distribution base. Later, the product is transported from these bases to the domestic market or to ports. Ethanol destined for the domestic market (fuel stations or retail resellers) is usually delivered by road [8].

Another alternative for the transport of ethanol is the use of a single load unit (e.g., a container) over multiple transport modes, which is called intermodal transport. Investment in new transhipment terminals can facilitate inland ship-rail-road combinations and save thousands of truck kilometers in congestion-sensitive areas, thus reducing the environmental impact. The downside of intermodal transport is that it requires more coordination than single mode transport, creating a need for the management of logistics systems. Intermodality has great importance for the development of nations by redistributing their internal transport systems in order to obtain a better position in the globalization process [9].

This study analyzed transport alternatives for different ethanol routes and compared them with the current logistics conditions in Brazil, by assessing the implications of transport infrastructure limits that aimed to increase ethanol competitiveness in national and international markets. A partial equilibrium model in the form of a mixed complementarity problem (MCP) applied to ethanol was proposed to assess three scenarios related to ethanol transport logistics in order to guide new transport projects capable of increasing the sector's competitiveness.

\section{Materials and Methods}

The pioneer showing the possibility of solving spatial equilibrium problems between different markets through mathematical programming proposed the problem of two spatially separated markets in a non-normative economy in a mathematical maximization program. This problem was formulated to maximize the area under all excess demand curves minus the area under all excess supply curves, minus total transportation costs, resulting in a competitive spatial equilibrium solution (i.e., based on the resulting intersection areas of the curves of these three variables) [10].

Using supply and demand functions is possible to obtain spatial and atemporal dimensions for price, production, utilization factors and consumption determined by means of a quadratic programming chart [11].

In partial equilibrium models, the direct impacts of trade policy in a given market are analyzed. Because ethanol is an agricultural commodity, its trade goes through the origin and destination and is subject to elasticity effects; hence, partial (or spatial) equilibrium models best suit the purpose of this study [11].

\subsection{Model Data}

The ethanol transportation routes to be analyzed were initially defined based on ethanol supply and demand data. These regions were selected according to their relevance to the product's commercial dynamics, by examining the behavior of the following variables in 2013: ethanol production, average output, planted area, exports, consumption and industrial capacity of sugar-alcohol plants. The regions included in the model were defined based on the relevance of these variables to them. The purpose was to characterize ethanol market dynamics in those regions, 
where, as believed, the highest potential for the sugar-alcohol industry was concentrated.

The central south region was selected because it is responsible for over $90 \%$ of ethanol production in Brazil. The states comprising the supply regions are São Paulo, Goiás and Mato Grosso do Sul, with the state of São Paulo responsible for more than $50 \%$ of total ethanol production. The states of Goiás and Mato Grosso do Sul combined produce approximately $22 \%$ of total Brazilian ethanol [12]. The state of São Paulo is divided into three subregions: subregion 1 represents the northwest of the state, subregion 2 represents the northeast of the state and subregion 3 represents the southern part of the state.

Excess supply (demand) regions are those in which ethanol production exceeds (is lower than) the volume consumed. Therefore, although the state of Minas Gerais is the third largest producer, it consumes about $90 \%$ of its production and its flow is insufficient to be considered to be an excess supply region. The northeast and south regions and state of Rio de Janeiro are responsible for consuming the greatest proportion of surplus ethanol produced in the central south region, and therefore are considered to be destination regions.

Regarding international demand, the following countries were selected: the United States, South Korea, the Netherlands and the rest of the world (ROW). The United States is the world's leading ethanol producer and has the largest import share in this market. South Korea and the Netherlands, according to export data, are the second and third largest importers of Brazilian ethanol, respectively [2].

The following variables comprise the model: production, consumption, domestic and international trading prices, freight of different transport modes and price elasticity of supply/demand. The base year of the variables is 2013. The source of production data was the Brazilian Institute of Geography and Statistics (2013) [13]. The source of consumption and domestic and international trading prices data was the National Agency of Petroleum, Natural Gas and Biofuels [7].
Price elasticity of supply/demand was extracted from the studies carried out by Beiral [14], Boff [15] and Luchansky and Monks [16].

Scenario 1 is a base scenario where the fees on the road and road-railroad routes are equal to those currently charged. For scenario 2, a 15\% decrease (the $15 \%$ discount was adopted based on interviews with the main players in the ethanol industry) in railroad transportation freight is proposed, thus changing the transportation dynamics of the routes. Scenario 3 represents a future situation where the use of railroads, road-railroads and road-pipeline multimodality is compared, assuming that the Logum project is already in operation.

\subsection{MCP for Brazilian Ethanol}

An MCP consists of a simultaneous equations system (that could be linear or non-linear), which is described as inequalities, whose inputs are the supply and demand functions [1]. The MCP proposed to analyze the Brazilian ethanol market is presented next:

Contents:

$i$ : ethanol supply regions $(i=1,2,3, \ldots, 5) ; j$ : ethanol domestic consumption regions $(j=1,2,3) ; k$ : ethanol international demand regions $(k=1,2,3) ; r$ : ethanol transportation routes $(r=1,2, \ldots, 18)$.

Variables:

$p_{i}$ : offer price; $p_{j}$ : domestic consumption price; $p_{k}$ : international demand price; $x_{i}$ : quantity offered; $y_{j}$ : domestic consumption; $y_{k}$ : international demand consumption; $\theta_{i j}$ : domestic volume transported; $\theta_{i k}$ : international volume transported.

Parameters:

$t_{i j}$ : domestic transportation cost; $t_{i k}$ : international transportation cost; $\partial_{i}$ : shadow price in supply region $i$ (for ethanol); $\varphi_{j}$ : shadow price in consumption region $j ; \varphi_{k}$ : shadow price in consumption region $k$.

Observing the equations below, it is noted that the symbol " $\perp$ " means that at least one of adjacent inequalities should be satisfied as a strict inequality. Eqs. (4) and (5) are thus described because of a 
complementarity formality to satisfy the Karush-Kuhn-Tucker conditions. In this case, scenario 2 proposes a discount to the railroad freight fee.

$$
\begin{gathered}
0 \leq \partial_{i} \perp \sum_{j}^{J} \theta_{i j}+\sum_{k}^{K} \theta_{i k} \leq x_{i} \\
0 \leq \varphi_{j} \perp y_{j} \leq \sum_{i}^{I} \theta_{i j} \\
0 \leq \sigma_{k} \perp y_{k} \leq \sum_{i}^{I} \theta_{i k} \\
0 \leq \theta_{i j} \perp p_{i}+t_{i j} \geq p_{j} \quad \forall_{i, j} \\
0 \leq \theta_{i k} \perp p_{i}+t_{i k} \geq p_{k} \quad \forall_{i, k}
\end{gathered}
$$

The $\operatorname{tax}_{i k}$ and $\operatorname{tax}_{i j}$ fees represent a $15 \%$ discount on the rail freight rate and were already added following the zero profit condition presented in Eqs. (6) and (7), where a new parameter is incorporated. The fee has implications only for the flows destined for the international market, preventing the zero profit condition [17]. In the current proposal, this fee represents the transportation variation cost and thus:

$$
\begin{array}{ll}
\left(p_{i}+t_{i k}\right) \times\left(1+\operatorname{tax}_{i k}\right) \geq p_{k} \quad & \forall_{i, k} \\
\left(p_{i}+t_{i j}\right) \times\left(1+\operatorname{tax}_{i j}\right) \geq p_{j} \quad \forall_{i, j}
\end{array}
$$

The MCP developed for this study was processed by using the General Algebraic Modeling System computational program [18].

\section{Results}

Table 1 showed the ethanol trading flows destined for the domestic market for each transportation route. Routes R1, R3, R4, R5 and R6 have the optimum transportation cost: R1, R3 and R5 are direct road routes, whereas $\mathrm{R} 4$ and $\mathrm{R} 6$ are road-railroad transportation routes. According to the flow, for scenario 1's transportation destined for the domestic market, $46 \%$ of routes are transported through the road mode, whereas $54 \%$ use multimodality.

Table 2 showed the routes destined for the international market.

Regarding the volumes destined for the international market in scenario 1 , most routes are transported by using multimodality (78\%), whereas the direct road mode is responsible for $22 \%$ of the transported volume. In scenario $2, \operatorname{tax}_{i k}$ and $\operatorname{tax}_{i j}$ fees were added, representing a discount of $15 \%$ in road freight amount, to analyze the extent to which a discount would affect the choice for multimodality. Table 3 showed the ethanol trading flows destined for the domestic market for each transportation route.

Regarding the volumes transported destined for the domestic market in scenario 2, 23\% are transported via the direct road mode, whereas $77 \%$ is multimodal.

For flows destined for the northeast region, the optimum transportation mode is still road (100\%), originating from the state of Goiás; however, for

\begin{tabular}{|c|c|c|c|c|c|c|}
\hline \multirow{2}{*}{ Origin } & \multirow{2}{*}{ Destination } & \multicolumn{5}{|c|}{ Routes $\left(\mathrm{m}^{3}\right)^{*}$} \\
\hline & & $\mathrm{R} 1$ & $\mathrm{R} 3$ & $\mathrm{R} 4$ & $\mathrm{R} 5$ & R6 \\
\hline Subregion 1 & South & & & 945.72 & & \\
\hline Subregion 1 & Rio de Janeiro & & & & 53.20 & \\
\hline Subregion 2 & Rio de Janeiro & & & & & 148.18 \\
\hline Subregion 3 & South & & 810.00 & & & \\
\hline Goias & Northeast & 822.15 & & & & \\
\hline Goias & Rio de Janeiro & & & & & 845.18 \\
\hline Total & & 822.15 & 810.00 & 945.72 & 53.20 & 993.36 \\
\hline
\end{tabular}
routes destined for the south region and the state of Rio de Janeiro, the optimum result is an enhanced use of multimodal routes. Table 4 showed the results for scenario 2 for the international market.

Table 1 Scenario 1: ethanol trading flows destined for the domestic market per transportation route in thousands of cubic meters.

* Routes R1, R3 and R5 are road routes, whereas routes R4 and R6 are multimodal routes.

Source: research data (2016). 
Table 2 Scenario 1: ethanol trading flows destined for the international market per transportation route in thousands of cubic meters.

\begin{tabular}{|c|c|c|c|c|c|}
\hline \multirow{2}{*}{ Origin } & \multirow{2}{*}{ Destination } & \multicolumn{4}{|c|}{ Routes $\left(\mathrm{m}^{3}\right)^{*}$} \\
\hline & & $\mathrm{R} 8$ & R9 & R11 & $\mathrm{R} 13$ \\
\hline Subregion 1 & The United States & 406.90 & & & \\
\hline Subregion 2 & The Netherlands & & 169.11 & & \\
\hline Subregion 2 & South Korea & & & 371.45 & \\
\hline Subregion 2 & ROW & & & & 53.99 \\
\hline Mato Grosso do Sul & The United States & $1,697.66$ & & & \\
\hline Total & & $2,104.56$ & 169.11 & 371.45 & 53.99 \\
\hline
\end{tabular}

* Routes R9, R11 and R13 are road routes, whereas the route R8 is multimodal route.

Source: research data (2016).

Table 3 Scenario 2: ethanol trading flows destined for the domestic market per transportation route in thousands of cubic meters.

\begin{tabular}{lllll}
\hline \multirow{2}{*}{ Origin } & Destination & \multicolumn{2}{c}{ Routes $\left(\mathrm{m}^{3}\right)^{*}$} & $\mathrm{R} 6$ \\
\cline { 3 - 4 } & & $\mathrm{R} 1$ & $\mathrm{R} 4$ & \\
\hline Subregion 1 & South & & 781.14 & 166.05 \\
Subregion 2 & South & & & \\
Subregion 2 & Rio de Janeiro & & 809.94 & \\
Subregion 3 & South & 819.83 & & 849.03 \\
Goias & Northeast & & & $1,048.98$ \\
Goias & Rio de Janeiro & 819.83 & $1,757.13$ & \\
\hline Total & &
\end{tabular}

${ }^{*}$ Route R1 is road route, whereas routes R4 and R6 are multimodal routes.

Source: research data (2016).

Regarding the routes destined for the international market, for all optimum routes, the model found that the best transporting option is multimodality. Therefore, R8, R10, R12 and R14 are competitive routes. Compared with scenario 1 , it is thus observed a disproportion regarding the distribution of transport modes. In this scenario, only $13 \%$ of routes are transported via direct roads, whereas $36 \%$ used highways as the main transportation mode in scenario 1.

Table 5 showed the results for scenario 3, where four transportation routes were added (R15, R16, R17 and R18) for the international market through the pipeline mode. For the road-railroad routes, the railroad freight prices used were equal to those currently charged, as in scenario 1. The purpose of this scenario was to examine the effect of implementing pipelines on multimodality.

Scenario 3 shows five competitive routes for the flows destined for the domestic market. Of these, three are by highways and two are multimodal; hence, according to the volume transported, $50 \%$ of scenario 3 's routes destined for the domestic market use the road mode and 50\% use multimodality. The domestic transportation in scenario 3 is therefore similar to that in scenario 1 , because the $15 \%$ discount on railroad freight fee is not applied in either case. Therefore, it can be concluded that lacking these fees makes the road mode more competitive for ethanol transportation to the domestic market.

Table 6 showed the results for scenario 3 regarding transportation for the international market. Here, four routes were added, namely R15, R16, R17 and R18, destined for the United States, the Netherlands, South Korea and ROW, respectively, using the road-pipeline multimodal option.

Regarding the competitive routes identified in scenario 3 for the international market, of the three options, the road mode is not competitive; thus, in this scenario, only multimodal routes for the international 
Table 4 Scenario 2: ethanol trading flows destined for the international market per transportation route in thousands of cubic meters.

\begin{tabular}{|c|c|c|c|c|c|}
\hline \multirow{2}{*}{ Origin } & \multirow{2}{*}{ Destination } & \multicolumn{4}{|c|}{ Routes $\left(\mathrm{m}^{3}\right)^{*}$} \\
\hline & & $\mathrm{R} 8$ & $\mathrm{R} 10$ & $\mathrm{R} 12$ & $\mathrm{R} 14$ \\
\hline Subregion 1 & The United States & 402.07 & & & \\
\hline Subregion 1 & The Netherlands & & 168.80 & & \\
\hline Subregion 1 & ROW & & & & 55.97 \\
\hline Subregion 2 & Korea & & & 377.25 & \\
\hline Mato Grosso do Sul & The United States & $1,702.16$ & & & \\
\hline Total & & $2,104.23$ & 168.80 & 377.25 & 55.97 \\
\hline
\end{tabular}

${ }^{*}$ Routes R8, R10, R12 and R14 are multimodal routes.

Source: research data (2016).

Table 5 Scenario 3: ethanol trading flows destined for the domestic market per transportation route in thousands of cubic meters.

\begin{tabular}{|c|c|c|c|c|c|c|}
\hline \multirow{2}{*}{ Origin } & \multirow{2}{*}{ Destination } & \multicolumn{5}{|c|}{ Routes $\left(\mathrm{m}^{3}\right)^{*}$} \\
\hline & & $\mathrm{R} 1$ & R3 & $\mathrm{R} 4$ & R5 & R6 \\
\hline Subregion 1 & South & & & 929.90 & & \\
\hline Subregion 1 & Rio de Janeiro & & & & 180.99 & \\
\hline Subregion 3 & South & & 812.40 & & & \\
\hline Goias & Northeast & 814.68 & & & & \\
\hline Goias & Rio de Janeiro & & & & & 857.60 \\
\hline Total & & 814.68 & 812.40 & 929.90 & 180.99 & 857.60 \\
\hline
\end{tabular}

${ }^{*}$ Routes R1, R3 and R5 are road routes, whereas routes R4 and R6 are multimodal routes.

Source: research data (2016).

Table 6 Scenario 3: ethanol trading flows destined for the international market per transportation route in thousands of cubic meters.

\begin{tabular}{|c|c|c|c|c|c|c|}
\hline \multirow{2}{*}{ Origin } & \multirow{2}{*}{ Destination } & \multicolumn{5}{|c|}{ Routes $\left(\mathrm{m}^{3}\right)^{*}$} \\
\hline & & $\mathrm{R} 8$ & $\mathrm{R} 15$ & R16 & $\mathrm{R} 17$ & $\mathrm{R} 18$ \\
\hline Subregion 1 & South Korea & & & & 299.12 & \\
\hline Subregion 2 & The United States & & 431.60 & & & \\
\hline Subregion 2 & The Netherlands & & & 174.77 & & \\
\hline Subregion 2 & South Korea & & & & 84.14 & \\
\hline Subregion 2 & ROW & & & & & 54.71 \\
\hline Mato Grosso do Sul & The United States & $1,696.22$ & & & & \\
\hline Total & & $1,696.22$ & 431.60 & 174.77 & 383.26 & 54.71 \\
\hline
\end{tabular}

${ }^{*}$ Route R8 is road-railroad multimodal route, whereas R15, R16, R17 and R18 routes are road-pipeline multimodal routes.

Source: research data (2016).

market are competitive. Therefore, the result for scenario 3 is similar to that for scenario 2 in that competitive routes destined for the foreign market are 100\% multimodal. Finally, scenario 3 points out that, as in scenario 2, multimodal routes could be more competitive than road routes; in this scenario, $71 \%$ of competitive routes are multimodal, whereas only $29 \%$ are road routes.

The results for scenario 1 point out the higher use of multimodality (64\%) compared with direct road transportation (36\%) for ethanol handling. However, when a $15 \%$ discount is applied to railroad freight fees (scenario 2), multimodality becomes more competitive $(87 \%)$ and thus the most efficient option. Note that in scenario 2, a major change in the means of transportation occurs in routes destined for exports. In scenario 1, approximately $78 \%$ of the routes destined for the international market were transported by using 
multimodality compared with $100 \%$ of routes in scenario 2. Hence, transportation for Santos port via direct roads is less competitive. Further, in scenario 3, when pipelines are added for the foreign market, multimodal routes are also more competitive than the use of highways.

The major difference observed in the three scenarios between adopting multimodality and using only the road mode can be seen in the transportation destined for Santos port, where in scenario 2, 100\% of routes indicate that multimodality is more competitive for this destination. Regarding the domestic market, when the three scenarios are compared, $40 \%$ of routes are more competitive when using the direct road mode compared with $60 \%$ for multimodality. This finding indicates that multimodality is more competitive for domestic flows, meaning that new investment in multimodal infrastructure is needed to increase the use of multimodality on domestic consumption routes.

\section{Discussion}

From these results, it is possible to identify what is actually practiced in the current scenario of Brazilian ethanol and what could be proposed with the intention of intensifying the market of a fuel considered as a source of clean energy and thereby take advantage of all possible environmental gains that this would entail.

In addition to this, the results show how to optimize ethanol flows, since in 2017 the supply of ethanol in Brazil was compromised; this could be considered absurd given that Brazil is the second largest producer of ethanol in the world.

The literature shows that an effective logistical planning can generate economies of scale, but in addition, Brazil is beginning a problem with shortages of this biofuel, generating dependence on imports from other producing countries, which implies a series of payments of extra taxes that increase the product in the country.

This work was important in predicting the optimal transportation and commercialization flows. It is evident that current Brazil faces a very divergent reality from what would be considered ideal, so that the agents and promoters of politics should be aware of future adversities that may arise.

\section{Conclusions}

Agricultural cargo transportation is a costly activity because the products have low added value. This means that the transportation cost comprises a large proportion of total cost, affecting competitiveness. Brazil currently faces the risk of a logistics blackout, as well as challenges regarding storage and transportation capacity. For ethanol in particular, although Brazil is the world's second largest producer, the shortcomings of its logistics system is making the country lose competitiveness compared with major global players.

Investment is thus necessary, not only in transportation infrastructure, but also in the entire logistics chain, given the importance of the logistics factor for agricultural cargo. Moreover, new public policies that promote the use of multimodality as a means to obtain competitive edge must be adopted by the main players of the industry. Multimodality is more competitive, as it reduces the cost of railroad transportation and encourages implementing a new pipeline system to increase transportation flows.

This study is novel in applying a partial equilibrium model to test the multimodal transportation of ethanol. However, future studies could build a spatial equilibrium model whose scope is only the domestic market or a second product, such as gasoline, the main competitor to ethanol in Brazil.

One of the limitations of the model is that it disregards US ethanol subsidies; as the study analyzed domestic market flows, US subsidies were not included in the model. Note that Brazilian ethanol could be more competitive if US subsidies were not applied; therefore, future analysis could be carried on to examine the effect of subsidies on Brazilian ethanol. 


\section{Acknowledgments}

The authors appreciate the Coordination for the Improvement of Higher Education Personnel (CAPES) for financial support, the Institute of Economics and the School of Agricultural Engineering at UNICAMP for having made possible the realization of this research.

\section{References}

[1] Oliveira, A. L. R. 2011. "The Logistics System and the Impacts of Segregating Diferente Grains: Challenges for Brazilian Agribusiness." Ph.D. thesis, University of Campinas, Campinas, SP, Brazil. (in Portuguese)

[2] Brazil. 2014. Ministry of Agriculture, Livestock and Food Supply. National Supply Company. CONAB. Projections of Agribusiness: Brazil 2009-2010 to 2019-2020. Brasília: Mapa/ACS. Accessed December 12, 2014. http://goo.gl/M6YDyq. (in Portuguese)

[3] Renewable Fuels Association (RFA). 2014. "Monthly U.S. Fuel Ethanol Production/Demand." Accessed January 2, 2015. http://ethanolrfa.org/pages/monthlyfuel-ethanol-production-demand.

[4] Grabara, J., Kolcun, M., and Kot, S. 2014. "The Role of Information Systems in Transport Logistics." Int. J. Edu. Res. 2 (2): 1-8.

[5] Milanez, A. Y., Nyko, D., Garcia, J. L. F., and Xavier, C. E. O. 2010. Logistics for Ethanol: Current Situation and Future Challenges. BNDES Setorial. Rio de Janeiro: BNDES, 31. (in Portuguese)

[6] Ballou, R. H. 2004. Supply Chain Management/Business Logistics. São Paulo: Atlas. (in Portuguese)

[7] National Agency of Petroleum, Natural Gas and Biofuels (ANP). 2012. Statistical Yearbook 2012. Accessed June 23, 2015. http://www.anp.gov.br. (in Portuguese)

[8] Oliveira, A. L. R. 2015. Ethanol Logistics in Brazil, edited by Filho, F. S. Rio de Janeiro: Elsevier, 9-33. (in
Portuguese)

[9] Dekker, R., Bloemhof, J., and Mallidis, I. 2012. "Operations Research for Green Logistics-An Overview of Aspects, Issues, Contributions and Challenges." Europe. J. Operat. Res. 219 (3): 671-9.

[10] Samuelson, P. A. 1952. "Spatial Price Equilibrium and Linear Program.” Amer. Econ. Rev. 42 (3): 283-303.

[11] Takayama, T., and Judge, G. G. 1971. Spatial and Temporal Price and Allocation Models. Amsterdam: North Holland Publishing Co..

[12] Brazilian Sugarcane Industry Association (UNICA). 2014. "Production and Milling History." Accessed January 23, $2015 . \quad$ http://www.unicadata.com.br/historico-deproducao-e-moagem.php?idMn=31\&tipoHistorico=2. (in Portuguese)

[13] Brazilian Institute of Geography and Statistics (IBGE). 2013. "Political-Administrative Division." Accessed June 13, 2013. http://www.ngb.ibge.gov.br/Default. aspx?pagina=divisao. (in Portuguese)

[14] Beiral, P. R. S. 2011. "The Brazilian Ethanol Market: Concentration and Market Power from the Perspective of the New Empirical Industrial Organization.” M.Sc. thesis, Luiz de Queiroz College of Agriculture, University of São Paulo, Piracicaba, SP, Brazil. (in Portuguese)

[15] Boff, H. P. 2010. "Modeling the Brazilian Ethanol Market: How Flex-Fuel Vehicles Are Shaping the Long Run Equilibrium.” Presented at IAEE's 2010 International Conference, Rio de Janeiro, RJ, Brazil. (in Portuguese)

[16] Luchansky, M. S., and Monks, J. 2009. "Supply and Demand Elasticities for the United States Ethanol Market." Energ. Econ. 31 (3): 403-10.

[17] Bishop, P. M., Nicholson, C. F., and Pratt, J. E. 2001. "Tariff-Rate Quotas: Difficult to Model or Plain Simple." Trade Working Papers, East Asian Bureau of Economic Research.

[18] Brooke, A., Kendrick, D., and Meerraus, A. 1995. GAMS: A User's Guide. Release 2.25. Redwood: The Scientific Press, 289. 